\title{
Can thematic roles leave traces of their places?
}

\author{
Franklin Chang*,a, Kathryn Bock ${ }^{\mathrm{b}}$, Adele E. Goldberg ${ }^{\mathrm{b}}$ \\ ${ }^{a}$ Max Planck Institute for Evolutionary Anthropology, Deutscher Platz 6, 04103 Leipzig, Germany \\ ${ }^{\mathrm{b}}$ Beckman Institute, University of Illinois at Urbana-Champaign, 405 North Mathews Avenue, \\ Urbana, IL 61801, USA
}

Received 28 August 2002; revised 12 May 2003; accepted 11 June 2003

\begin{abstract}
An important question in the study of language production is the nature of the semantic information that speakers use to create syntactic structures. A common answer to this question assumes that thematic roles help to mediate the mapping from messages to syntax. However, research using structural priming has suggested that the construction of syntactic frames may be insensitive to variations in thematic roles within messages (Cognition 35 (1990) 1; Psychological Review 99 (1992) 150). Because these studies involved structural alternations whose syntax covaries with the order of thematic roles, it is difficult to assess any independent contribution that role information may make to the positioning of phrases. In this study, we primed the order of the roles without changing the syntactic structure of the sentences produced, and found that the order of the roles was influenced by the priming manipulation. This implies that thematic roles or the features that differentiate them are active within the mapping between messages and sentence structures. (C) 2003 Elsevier B.V. All rights reserved.
\end{abstract}

Keywords: Language production; Thematic roles; Syntax; Structural Repetition

\section{Introduction}

When we speak, we typically try to convey some notion or set of notions in a sequence of words. Both of these tasks, conveying notions linguistically and developing a sequence of words for doing so, have been argued to depend on their own specialized representations (Garrett, 1988). The mapping from notions to language is constrained in some fashion by linguistic semantics. The sequencing of words is constrained by syntactic structure, which represents hierarchical and linear relationships among phrases. Our goal

\footnotetext{
* Corresponding author.

E-mail address: fchang@langprod.cogsci.uiuc.edu (F. Chang).
} 
in this work was to evaluate the viability of a basic assumption about how these different kinds of constraints are linked.

Structural constraints on their own cannot ensure that a sentence conveys the intended meaning, and the violations of sentence meaning seen in word exchanges and other speech errors indicate that, in fact, structural integrity is not incompatible with semantic perfidy. The implication is that another set of processes mediates between intended messages and syntax. For example, the relationship between man and $\operatorname{dog}$ is different in the sentences The man bit the dog and The dog bit the man. In the first sentence, the man plays the role of agent and the dog plays the role of patient, while in the second sentence the fillers of the roles of the verb bite are reversed. Moreover, the same role can occur in different structural and serial positions (compare the active The man bit the dog with the passive The dog was bitten by the man). Accordingly, the cognitive mechanisms for encoding language must provide some means for securing intended relationships among entities across variations in the positions in which they occur. In theories of language production the maintenance of this equation is the responsibility of functional processing (Garrett, 1988).

The nature of the functional equation that is formulated during production is unknown, but one hypothesis involves the argument-structure construction (Goldberg, 1995). An argument-structure construction is a scheme that relates an array of thematic roles (such as agent, goal, and patient) to a form, conceived as a set of grammatical relations or formal categories. For example, in the sentence The man gave the girl the present, the man fills the agent role, the girl the recipient role, and the present the theme role. This double-object dative construction relates the three roles to three grammatical relations (corresponding to the subject, direct object, and second object, respectively). The construction thereby provides a mapping relating the agent to subject, the recipient to direct object, and the patient to second-object position.

Some way of mapping thematic roles to structural positions is a part of most linguistic frameworks, but the constructional approach differs in certain respects. In most other theories of grammar, syntax is a projection from lexical elements (Bresnan, 1982; Chomsky, 1981; Grimshaw, 1990; Levin \& Rappaport Hovav, 1995; Pinker, 1989). In these approaches, lexical entries contain information about semantics and syntax, and through general structural principles (e.g. X-bar syntax) or parameters (e.g. head direction), the lexical entries are used to build syntactic trees. Constructional approaches argue that there are generalizations about thematic role arrays that are not associated with particular lexical items, but with structural configurations (e.g. Bencini \& Goldberg, 2000). For example, suppose there is a new kind of squirt-gun called a purt. If someone used the purt's spray to push an object across a surface, English allows the action to be described with a verb derived from this particular noun (e.g. The man purted the ball across the table). In traditional approaches, this ability would require that purt (and every other denominal verb that can be used in this way) have a separate lexical entry licensing its use in this structure. In constructional approaches, the ability to generate this novel sentence is due to the existence of a specific structural configuration, the caused-motion construction. The construction represents a pairing of a thematic role array (i.e. an abstract relational meaning) with a surface syntactic structure. In the example, the array consists of an agent (the man) which causes a theme (the ball) to 
move along a path (across the table) and the surface syntactic structure consists of SUBJECT VERB OBJECT OBLIQUE. Because the construction is separate from the lexical entry for the verb, there is no requirement that a verb have a lexical entry for just this pairing. With respect to sentence production, the sets of roles provide the semantic support that is needed for functional processing to mediate the mapping from thought to language independent of specific lexical items. ${ }^{1}$

Constructions also allow for a plausible account of the phenomenon of structural repetition. Structural repetition is seen in speakers' tendencies to reuse a previously produced sentence structure in a new, otherwise unrelated utterance. In experimental models of this phenomenon (beginning with Bock, 1986), after speakers produce a doubleobject dative sentence like The artist showed the police captain a sketch, they are more likely to describe a subsequent event using another double-object sentence than if they had produced a structurally different priming sentence (such as The artist showed a sketch to the police captain). That is, having formulated one double-object structure, speakers are prone to use another one to describe an unrelated situation (e.g. The children are giving the teacher flowers). Conversely, the production of prepositional datives is associated with an increased likelihood of using prepositional datives later on (e.g. The children are giving flowers to the teacher). Speakers thus tend to generalize structure from one sentence to another. Crucially, they do so regardless of whether the verb (or other words) used in the structurally primed utterance is the same as the verb in the priming sentence. Although the repetition of words increases the magnitude of structural priming (Cleland \& Pickering, 2002; Pickering \& Branigan, 1998), it is not essential to the occurrence of priming.

Despite its attractions as an account of functional processing generally and structural priming specifically, the constructional approach incorporates a problematic assumption that it shares with many other linguistic and psycholinguistic views. Specifically, it relies on thematic roles (or abstract relational meaning) in the mapping to structural positions in utterances. Standing in the way of role-based accounts of functional processing is evidence that structural priming appears not to hinge on the identity of thematic roles in prime and target sentences. Bock and Loebell (1990, Experiment 1) found that prepositional locatives (e.g. The wealthy widow drove the Mercedes to the church) primed prepositional dative picture descriptions to the same degree that prepositional datives (e.g. The wealthy widow gave the Mercedes to the church) primed other prepositional datives. The prepositional locative and the prepositional dative have a similar structural configuration (NP [V NP [P NP $\left.]_{\mathrm{PP}}\right]_{\mathrm{VP}}$ ), but they arguably differ in the event role of the prepositional argument. In the prepositional locative, the prepositional phrase might be said to encode the location of the action, while in the dative it might be said to encode the recipient of the action.

A second experiment found even stronger evidence against a purely thematic construal of structural repetition (Bock \& Loebell, 1990, Experiment 2). Locatives like

\footnotetext{
${ }^{1}$ Nothing hinges on the idea that the relational meaning conveyed by argument structure constructions is captured by roles per se. The relational meaning can equally well be captured by decompositional structures such as X CAUSES Y to MOVE (to) Z. That is, roles in the present discussion can alternatively be interpreted as slots (e.g. $\mathrm{X}, \mathrm{Y}, \mathrm{Z}$ ) in an abstract relational predication.
} 
The 747 was landing by the control tower primed passive utterances as much as passives like The 747 was alerted by the control tower. The locatives and passives had similar syntactic structures (NP $\left[\mathrm{AUX} V[\mathrm{P} \mathrm{NP}]_{\mathrm{PP}}\right]_{\mathrm{VP}}$ ), but the locatives had agents as subjects, while the passives had patients as subjects. These results suggest that structural repetition does not depend on overlap in the thematic roles of prime and target sentences.

More puzzling from the standpoint of the constructional hypothesis is that role overlap did not promote structural repetition: locatives and passives were equally effective primes, suggesting that the roles of the constituents did not influence their positioning. Instead, Bock, Loebell, and Morey (1992) proposed that basic conceptual features of role fillers help to regulate functional mapping. Bock et al. varied the animacy of the subjects of active and passive sentences, and found that the presence of an animate subject in priming sentences increased the tendency to make animate entities the subjects of target sentences. Because this type of priming occurred over and above the general tendency to reuse the active or passive structure of priming sentences, Bock et al. concluded that thematic roles as such may not participate in functional mapping. Instead, conceptual features of the rolefilling concepts (like animacy) promoted similar positioning - as subjects - of like constituents in the targets.

The paradox in these findings is that aspects of both sentence meaning (the animacy of subjects) and sentence structure (active and passive form) appeared to be susceptible to priming, when the functional mapping itself was not. The findings clash with theories in which the mapping between meaning and form involves a specified set of thematic roles. Though the results can be reconciled with abstract decompositions (along the lines of $\mathrm{X}$ CAUSES Y to MOVE to $\mathrm{Z}$ ) as it stands there is no priming evidence that selectively supports any role-based treatment of functional mapping.

One feature of existing research on structural repetition may serve to obscure any part played by thematic roles within the mapping from meaning to form. Because English typically confounds the structural position of a phrase with its thematic properties, it is difficult to create changes to the thematic properties of primes and targets without corresponding changes to their structural properties. For this reason, existing experiments orthogonally manipulated the correspondence between thematic roles and syntactic functions across primes and targets in just one sentence position, leaving the normal correlation in other positions intact. For example, in Bock et al. (1992), the animacy and agency of the subject were manipulated independently in the priming sentences, but of necessity, not in the targets: in the targets, a speaker's selection of an animate or an agent subject controlled the choice of the sentence structure and conversely, selection of a sentence structure controlled the animacy or agency of the subject. Such manipulations, relying on a single role variation to drive a change in functional processing, may be insufficiently powerful to create the consistent relational differences that would reveal the interaction of thematic roles and syntactic structure. In contrast, the structural components of repetition were supported by the entire gross configuration of the priming sentences.

Structural priming increases substantially when there is lexical and semantic overlap between prime and target sentences (Cleland \& Pickering, 2002; Pickering \& Branigan, 1998), suggesting that lexical support increases the likelihood of priming between sentences. Likewise, overlap in thematic roles may increase priming, according to findings 
from Hare and Goldberg (2000). Hare and Goldberg found evidence of thematic-role priming using the provide-with and the double-object constructions. The provide-with construction (e.g. The army provided the soldiers with blankets) has the same syntactic structure as the prepositional dative (NP $\left[\mathrm{V} \mathrm{NP}[\mathrm{P} \mathrm{NP}]_{\mathrm{PP}}\right]_{\mathrm{VP}}$ ), but the object argument is the recipient and the second-object argument is a theme. This makes the order of the roles the same as the order in the double-object construction, which also puts the recipient directly after the verb and before the theme. Hare and Goldberg found that provide-with sentences primed double-object expressions as much as double-object priming sentences did. This suggests that the order of thematic roles can be primed. However, because Hare and Goldberg used role fillers that differ in animacy (animate recipients and inanimate themes), their results could be explained in the same terms as Bock et al. (1992) rather than in terms of thematic roles proper.

To recap, thematic role arrays can be used to explain how sets of notions are mapped to structural relations in functional processing. This type of explanation is challenged by evidence which suggests that, in structural priming, relationally relevant conceptual features of the concepts expressed (such as animacy) steer the mapping, and not thematic roles. However, in experimental work on structural priming, thematic role variations are normally accompanied by differences in syntactic structure, making it difficult to isolate the part that thematic roles play in the production process. Since roles or abstract relational representations are important in linguistic theories of the mapping between meaning and form, it is imperative to evaluate their contribution under better controlled conditions.

To achieve a straightforward test of thematic-role priming without the confounding influences of animacy or structural changes, we used constructions in which the order of constituents varies within the same syntactic structures and in which the critical arguments are both inanimate. These constructions are found in the locative alternation (Anderson, 1971; Levin, 1993; Rappaport \& Levin, 1985), also called the spray-load alternation. This alternation varies the order of the theme (the object that moves) and the location (the place that is moved to), both of which are typically inanimate. For example, in The man sprayed wax on the car, wax is the theme and car is its final location. The alternative order puts the location before the theme, as in The man sprayed the car with wax. The structure in both cases is traditionally NP $\left[\mathrm{V} N \mathrm{NP}[\mathrm{P} \mathrm{NP}]_{\mathrm{PP}}\right]_{\mathrm{VP}}$, so priming of the structural configuration should not differ. But if the order of the roles matters, then we should find the theme-location order priming other theme-location orders more than the location-theme order. That is, The man sprayed wax on the car should prime the production of The workers scuffed dirt across the kitchen floor more than The workers scuffed the kitchen floor with dirt.

Since spray-load constructions are not easy to elicit reliably with picture description, we needed another task in which structural repetition occurs. One such task is Potter and Lombardi's rapid serial visual presentation (RSVP) sentence repetition paradigm (Potter \& Lombardi, 1998). In this paradigm, participants silently read from a computer screen sentences shown one word at a time at a fast rate. The participants then performed a distractor task before repeating the sentence aloud. Because of the normal difficulty of explicitly remembering the surface forms of sentences, along with the high speed of presentation and the intervening task, speakers sometimes changed the syntactic structure of the sentences. Using this procedure, Potter and Lombardi found a tendency to reuse previously produced structures, with participants tending to recall the sentence on a current 
trial in the grammatical structure used to recall a different sentence on the preceding trial. Potter and Lombardi attributed this to structural priming.

Using this paradigm, we tested two competing hypotheses. The first, which we call the roles hypothesis, says that thematic roles are a proper part of functional processing in language production. The second is the no-roles hypothesis, which claims that the functional processes that support sentence production do not recognize thematic roles as such, making it impossible to prime the roles themselves. In Experiment 1, the no-roles hypothesis predicts no difference in priming between the different orders of theme and location in the alternative forms of the locative alternation, while the roles hypothesis predicts just such a difference.

\section{Experiment 1: Locative alternation}

In this experiment, we tested whether thematic-role identity is sufficient to prime the order of noun phrases in sentences, within the same general structural configuration. For this purpose we used spray-load sentences with alternative orders of themes and locations as primes, and different spray-load sentences presented with the same or contrasting orders of thematic roles as the targets.

\subsection{Method}

\subsubsection{Participants}

Eighty-three students from the University of Illinois took part in the experiment, receiving partial credit toward fulfillment of an introductory psychology course requirement. A total of 80 students were included in the analyses. The remaining participants were excluded because of experimenter errors (two) or non-native English language (one).

\subsubsection{Materials}

There were 16 spray-load alternation items. Each item contained noun phrases representing a theme and location after the verb, either as the direct object or the object of a prepositional phrase. Two types of spray-load items were used, theme-location and location-theme. Theme-locations placed the theme in the object position and the location in a prepositional phrase with a directional preposition. Location-themes placed the location in the object position and the theme in a prepositional phrase with the preposition with. Items were formed by combining two pairs of these sentences, so that each item contained four sentences, two representing each order (location-theme and themelocation). The combinations of sentences were designed to minimize the semantic similarity of the actions conveyed. For example, liquid-propulsion actions like spray and splattered were paired with non-liquid-propulsion actions like jammed or engraved. Table 1 illustrates one item in four conditions, and Appendix A lists all of the experimental sentences.

In addition to the experimental items there were 288 filler sentences (including the 32 dative sentences from Experiment 2). The fillers came from a variety of constructions 
Table 1

Example of prime and target pairing for spray-load sentences in Experiment 1

\begin{tabular}{ll}
\hline Prime & Target \\
\hline $\begin{array}{l}\text { Theme-location } \\
\text { The maid rubbed polish onto the table. }\end{array}$ & Theme-location \\
Location-theme & The farmer heaped straw onto the wagon. \\
The maid rubbed the table with polish. & \\
Theme-location & Location-theme \\
The maid rubbed polish onto the table. & The farmer heaped the wagon with straw. \\
Location-theme & \\
\hline
\end{tabular}

including unaccusatives (The woman ran three miles a day), unergatives (The politician coughed), there structures (There were free cookies yesterday), truncated passives (The usual suspects were rounded up), clefts (It is strange to think that the Beaver has grown up), copulas (The beautiful child was as good as gold), tough movement structures (The anger of the crowd was hard to understand), locative inversion structures (On the table were pancakes and coffee), that complements (The professor believed that only half the class was enrolled), and infinitival complements (The students wanted to cancel class). The fillers were designed to avoid structures that might prime prepositional phrases at the ends of sentences, and to avoid lexical overlap with each other and with the target sentences.

Lists were assembled from the filler and experimental items so as to create what appeared to be a series of 320 unrelated sentences. Embedded in every list were 16 sequences of two sentences derived from the experimental items. These constituted the priming trials, each with a prime and target sentence. Eight versions of each prime-target pair were created (two priming types $\times$ two target types $\times$ two orders). The two prime and target types were the location-theme and theme-location forms of the experimental sentences, and the two orders were created by making the sentences that served as primes on one set of lists into the targets on another set. The priming sentence-type alternated across the item sequence, and the target structure alternated according to an ABBA scheme. The priming trials were separated by a total of 18 sentences (eight fillers, a prime and target pair from Experiment 2, and another eight fillers).

Eight different lists were used. A single sequence of the 16 experimental items was devised and rotated through the eight lists, with eight different starting points in the rotation, in order to distribute practice and fatigue effects across experimental items and conditions. The fillers (excepting the items for Experiment 2) were randomized, and the same random order was used in every list. The priming trials were separated by a total of 18 sentences (eight fillers, a prime and target pair from Experiment 2, and another eight fillers).

\subsubsection{Procedure}

Participants were tested individually, seated in front of a computer terminal in a soundattenuated room. Experimental trials were controlled by a Macintosh Quadra 800 running 


$\begin{array}{lc}200 \mathrm{msecs} & \text { The } \\ 100 \mathrm{msecs} & \text { politician } \\ 100 \mathrm{msecs} & \text { coughed } \\ 100 \mathrm{msecs} & \\ 0 \mathrm{msecs} & \\ 533 \mathrm{msecs} & \\ 100 \mathrm{msecs} & \\ 500 \mathrm{msecs} & \text { Two } \\ & \end{array}$

Fig. 1. The sequencing and timing of events in a single trial.

PsyScope software (Cohen, MacWhinney, Flatt, \& Provost, 1993) with the PsyScope button box. The monitor was an Apple Multiple Scan 17 Display (AK8 M2494). Participants viewed the screen from a comfortable viewing distance.

One sentence from the list was presented on every trial. Fig. 1 shows the sequence and timing of trial events. Each trial had three phases: a reading phase, a number comparison phase, and a speaking phase. These phases unfolded continuously, with the timing indicated in the figure, so that participants experienced an uninterrupted series of stimulus and response events.

The reading phase began with a $200 \mathrm{~ms}$ fixation prompt, which was a horizontal array of five asterisks in the center of the screen. The participants then silently read a sentence presented one word at a time, which they were instructed to remember for later recall. The words of the sentence were presented for $100 \mathrm{~ms}$ each in the center of the screen.

Next came the number comparison phase, which was designed to obstruct rehearsal of the to-be-remembered sentence and thereby decrease the likelihood of rote recall. In this phase participants saw a horizontal array of five single-digit numbers for $533 \mathrm{~ms}$, followed after $100 \mathrm{~ms}$ by a number written out as a word, which served as a probe. It was displayed for $500 \mathrm{~ms}$. A prompt for a yes or no response followed the probe, and participants were supposed to indicate by a button press whether the corresponding number had been in the list of digits. The prompt remained until the participant pressed either the left (mapped to no) or the right (mapped to yes) button on the button box. Feedback about the response 
appeared for $500 \mathrm{~ms}$ (a happy face for a correct response and a sad face for an incorrect response).

The final phase was speaking, when participants were to recall the sentence that they had seen in the reading phase. This phase began immediately after number comparison with a blank screen for $500 \mathrm{~ms}$. Production was prompted with the word "Repeat" centered on the screen, directing participants to produce the sentence that they had just seen. The word "Repeat" stayed on the screen until participants pressed the center button on the button box, to signal completion of the sentence.

Words and numbers were presented in 14-point Courier font. The spoken sentence responses of the participants were recorded on a Sony Digital Audio Tape Deck (DTCZE700) through a Shure head-worn microphone (SM10A) amplified by an Applied Research and Technology Professional Tube Mic Preamplifier.

From a participant's point of view, the sentences that constituted the primes and targets were not readily discriminable from the filler sentences. The participants were not told about any of the differences in the sentences across the various trials, or of potential relationships across consecutive trials. Objectively, however, filler-sentence trials differed from prime and target trials during the number-comparison phase. Filler trials had either yes or no answers, and on positive trials the to-be-verified number could appear anywhere in the array. Prime and target trials always had yes answers and the to-be-verified numbers were always either the leftmost or rightmost numbers in the number list, to decrease the occurrence of incorrect responses on these trials.

The experiment began with the presentation of the instructions on the screen. After the participants finished reading the instructions, the experimenter paraphrased them and led the participant through the trial sequence from the instructions. The participants then began the experiment, starting with eight filler trials that preceded the first experimental trial. Each experimental session took approximately 45 minutes.

\subsubsection{Design and scoring}

2.1.4.1. Design. Each participant received four items in each of the cells formed by crossing the factors of prime structure (theme-location and location-theme) and given target structure (theme-location and location-theme). Every item was seen by 12 participants in the four cells of the same design.

2.1.4.2. Scoring. The tapes of the experimental sessions were transcribed by editing a file that contained a list of the prime and target sentences as the participants had originally seen them. The sentences were edited so that they matched what the speakers had produced on the tapes, including partially produced words, rephrasing, and pauses.

The transcribed responses were categorized with respect to the constituents of the presented sentences and the structures of the utterances produced. Utterances could be scored either as location-theme (e.g. The witch doctor stuck the doll with pins) or themelocation (e.g. The witch doctor stuck pins into the doll). Location-theme responses had to fit the template "verb B with A" and theme-location the template "verb A PREP B", where the verb had to be the same as the presented verb, A was the noun phrase representing the given theme (e.g. pins), B was the noun phrase representing the location (e.g. the doll), and PREP was a preposition other than with. Pauses and minor changes in tense, number, and 
articles were ignored. Restarts, changes in the subject, and omission of content words (e.g. adjectives) were also ignored.

For target sentences, other kinds of changes in form (primarily content-word changes or additions to the verb phrase) were coded in two ways, strict and standard. On the strict coding scheme, all these changes caused responses to be excluded from the analyses. A looser coding was also applied to make the results more directly comparable to the coding schemes in Potter and Lombardi (1998) and in picture description tasks (Bock, 1989). We call this standard coding. It allowed utterances to be included if they could felicitously alternate between the theme-location and location-theme orders, regardless of fidelity to the presented sentence. This coding permitted changes to other alternating verbs and other content word changes. Priming sentences were scored according to strict criteria only.

A trial was considered valid if the prime was produced correctly (according to the strict coding criteria) and the target was produced in one of the two target structures (by strict or standard coding criteria). Strict coding yielded 522 valid trials (41\%) and standard coding yielded 598 valid trials (47\%). Invalid trials were the product of many kinds of changes (e.g. omissions of phrases, changes in content). Empty cells in the design were estimated with row and column means (Winer, 1971).

Analyses of variance were performed on the arc-sine transformed proportions of location-theme responses out of all location-theme and theme-location responses elicited from each participant or item in each cell of the design. Separate analyses were done for strict and standard codings. For these analyses, both participants and items were used as random factors, with prime type and target type as within-participant and within-item variables. To ensure that the statistical results were not due to estimation of empty cells, another set of analyses was performed on data formed by pooling the results within sets of three participants from the same cells of the design into one and treating these superparticipants as the random factor. The data from 72 participants were used to create 24 super-participants, which yielded no empty cells. For all statistical analyses, the results from the strict-coding data for individual participants will be reported, because the results for standard coding and for the super-participants analyses yielded the same outcomes. Differences were considered significant when their associated probabilities were less than or equal to 0.05 .

\subsection{Results}

Table 2 shows the raw counts and proportions of location-theme sentences produced out of all targets in each condition for both strict and standard coding. Participants were significantly more likely to produce location-theme sentences after location-theme primes $(0.515)$ than after theme-location primes $(0.473)(F 1(1,79)=9.46, F 2(1,15)=6.62)$. There was also a significant main effect of target sentence type $(F 1(1,79)=434.23$, $F 2(1,15)=740.79)$ because participants tended to use the sentence form that they had received, producing an average of 0.95 location-theme orders when they were given location-theme targets, compared to 0.03 location-theme orders given theme-locations targets. These two effects did not interact significantly $(F 1(1,47)=1.91$, 
Table 2

Proportions and counts of location-theme and theme-location versions of the locative alternation produced in Experiment 1

\begin{tabular}{|c|c|c|c|c|c|}
\hline \multirow[t]{3}{*}{ Prime form } & \multirow[t]{3}{*}{ Target form } & \multicolumn{4}{|c|}{ Proportions (and counts) of alternative response types produced } \\
\hline & & \multicolumn{2}{|l|}{ Strict coding } & \multicolumn{2}{|l|}{ Standard coding } \\
\hline & & Location-theme & Theme-location & Location-theme & Theme-location \\
\hline Location-theme & Location-theme & $0.977(129)$ & $0.023(3)$ & $0.966(143)$ & $0.034(5)$ \\
\hline Theme-location & Location-theme & $0.917(121)$ & $0.083(11)$ & $0.901(137)$ & $0.099(15)$ \\
\hline Location-theme & Theme-location & $0.053(7)$ & $0.947(125)$ & $0.084(13)$ & $0.916(141)$ \\
\hline Theme-location & Theme-location & $0.008(1)$ & $0.992(125)$ & $0.007(1)$ & $0.993(143)$ \\
\hline
\end{tabular}

$F 2(1,15)=2.18)$. Analyses using standard coding and super-participants (with strict coding) had similar outcomes.

Participants' performance on the number comparison task was excellent, with $93 \%$ correct on spray-load sentence trials and $90 \%$ on filler trials.

\subsection{Discussion}

The results show that speakers tended to use the primed order of arguments when they produced the target sentences, using the location-theme order more often when the location-theme order had been used in the prime, and the theme-location order more often when the theme-location order had been used in the prime. They did this regardless of which target sentence type they were given. This supports the hypothesis that the order of thematic roles matters in language production.

One issue is whether closed-class lexical overlap influenced priming. The themelocation construction uses a variety of prepositions to mark the location role (over, onto, into, around, on), while the location-theme construction uses only the preposition with. If the preposition with had increased the tendency to use the location-theme structure in the target, location-theme primes for location-theme targets should have been significantly more effective than theme-location primes for theme-location targets. They were not $(6 \%$ in the former, $4.5 \%$ in the latter). This suggests that spray-load priming was due primarily to the order of thematic roles, regardless of closed-class lexical overlap.

It might, however, be argued that the RSVP task is more sensitive to the order of thematic roles than the sentence-picture priming procedure, where effects of thematic roles have been absent. Notably, Potter and Lombardi (1998) found more priming of prepositional dative structures by prepositional datives than by prepositional locatives, in contrast to Bock and Loebell (1990). This could have been due to differences in the lexical content of Potter and Lombardi's goal/location phrases, because such variations in noun phrases can have consequences for the magnitude of priming irrespective of thematic role differences (see Bock et al., 1992). Alternatively, Potter and Lombardi's result could be ascribed to the sentence comprehension component of the RSVP task, which may enhance the contribution of role-relevant information. Since this second interpretation would undercut the support from Experiment 1 for the roles hypothesis, a second 
experiment used the RSVP paradigm to examine priming for dative sentences. The RSVP items in Experiment 2 incorporated dative primes and targets comparable to those from priming experiments that used the picture description task (Bock, 1989).

\section{Experiment 2: Dative alternation}

The second study examined the sensitivity of RSVP recall to differences in thematic roles when the content words of the prime and target sentences were controlled. The target sentences were transfer datives (e.g. A soldier offered his pal a cigarette) and benefactive datives (e.g. A soldier saved his pal a cigarette), and the priming sentences were of the opposite thematic type. Transfer datives have a verb that requires the preposition to in the prepositional form of the dative alternation (e.g. A soldier offered a cigarette to his pal), with object noun phrases representing a theme and a goal. Benefactive datives have a verb that requires the preposition for in the prepositional dative form (e.g. A soldier saved a cigarette for his pal), and noun phrases representing a theme and a beneficiary. Thus, there is a single thematic role variation. Specifically, the goal in a transfer dative is the beneficiary in a benefactive dative ( $p a l$ in the examples). If priming in the RSVP paradigm is more vulnerable to thematic role effects than priming in picture description, the structural priming observed between transfer and benefactive datives in the sentencepicture task (Bock, 1989) may be eliminated with RSVP.

\subsection{Method}

\subsubsection{Participants and procedure}

The participants and procedures were the same as in Experiment 1.

\subsubsection{Materials}

There were 16 dative items (drawn from priming sentences in Bock, 1989). Each contained two sets of sentences representing transfer datives and benefactive datives. Priming trials were constructed from sentence pairs drawn from each item. The primes occurred in both the prepositional and double-object structures, but the target dative was always in the double-object form. This was done to reduce the overall number of NP [V $\left.\mathrm{NP}[\mathrm{P} \mathrm{NP}]_{\mathrm{PP}}\right]_{\mathrm{VP}}$ structures in the experimental list as a whole (which included the items for Experiment 1). The pairings of prime and target were made so as to minimize the lexical and semantic overlap between the members of each pair, and were always different in thematic type (transfer or benefactive). Table 3 illustrates one item, and Appendix B lists all of the experimental sentences.

Eight versions of each prime-target pair were created, analogous to the construction of the items in Experiment 1, and assigned to lists using the same ordering and randomization schemes.

\subsubsection{Design and scoring}

The experimental design and scoring procedures followed those in Experiment 1. Prime and target utterances were scored either as prepositional datives (e.g. The artist showed 
Table 3

Prime and target pairings for one item from Experiment 2

\begin{tabular}{ll}
\hline Prime & Target \\
\hline $\begin{array}{l}\text { Prepositional dative (benefactive) } \\
\text { An artist drew a sketch for the police captain. }\end{array}$ & Transfer \\
$\begin{array}{l}\text { Double-object (benefactive) } \\
\text { An artist drew the police captain a sketch. }\end{array}$ & A soldier offered his pal a cigarette. \\
Prepositional dative (transfer) & Benefactive \\
An artist showed a sketch to the police captain. & A soldier saved his pal a cigarette. \\
Double-object (transfer) & \\
An artist showed the police captain a sketch. & \\
\hline
\end{tabular}

a sketch to the police captain) or double-object (e.g. The artist showed the police captain a sketch). Prepositional datives had to fit the template "verb A preposition B" and doubleobjects the template "verb B A" where A was the noun phrase representing the theme (e.g. the sketch), and $\mathrm{B}$ was the noun phrase representing the goal or beneficiary. In other respects the scoring was the same as in Experiment 1. Both strict and standard coding were done, with strict coding giving 448 valid trials (35\%) and standard coding giving 644 valid trials $(50 \%)$. Results from both the standard and strict coding are shown in Table 4. Analyses of variance for participants and items were carried out on the arc-sine transformed proportions of prepositional datives produced out of all prepositional and double-object datives. Prime type (prepositional dative or double-object dative) and target type (transfer or benefactive) were within-participant and within-item variables. As in Experiment 1, analyses were carried out on both the strict and standard coding data, and on individual participant and super-participant data. We report the inferential statistics based on standard coding results from the individual participants analyses only, because all analyses yielded the same patterns.

Table 4

Proportions and counts of prepositional and double-object datives produced in Experiment 2

\begin{tabular}{|c|c|c|c|c|c|}
\hline \multirow[t]{3}{*}{ Prime form } & \multirow[t]{3}{*}{ Target form } & \multicolumn{4}{|c|}{ Proportions (and counts) of alternative response types produced } \\
\hline & & \multicolumn{2}{|l|}{ Strict coding } & \multicolumn{2}{|c|}{ Standard coding } \\
\hline & & $\begin{array}{l}\text { Prepositional } \\
\text { dative }\end{array}$ & $\begin{array}{l}\text { Double-object } \\
\text { dative }\end{array}$ & $\begin{array}{l}\text { Prepositional } \\
\text { dative }\end{array}$ & $\begin{array}{l}\text { Double-object } \\
\text { dative }\end{array}$ \\
\hline $\begin{array}{l}\text { Prepositional dative } \\
\text { (benefactive) }\end{array}$ & Transfer & $0.058(6)$ & $0.942(98)$ & $0.113(17)$ & $0.89(133)$ \\
\hline $\begin{array}{l}\text { Double-object } \\
\text { (benefactive) }\end{array}$ & Transfer & $0.008(1)$ & $0.992(118)$ & $0.006(1)$ & 0.99 (177) \\
\hline $\begin{array}{l}\text { Prepositional dative } \\
\text { (transfer) }\end{array}$ & Benefactive & $0.056(6)$ & $0.944(102)$ & $0.096(15)$ & $0.904(141)$ \\
\hline $\begin{array}{l}\text { Double-object } \\
\text { (transfer) }\end{array}$ & Benefactive & $0(0)$ & $1.0(117)$ & $0.019(3)$ & $0.981(157)$ \\
\hline
\end{tabular}




\subsection{Results}

Table 4 shows the raw counts and the proportions of prepositional dative structures produced out of all datives in each condition. Given a prepositional dative prime, participants were significantly more likely to change the subsequent target to a prepositional dative sentence $(0.105)$ than they were given a double-object prime $(0.012)(F 1(1,79)=15.62, F 2(1,15)=14.55)$. Target type (transfer or benefactive) did not affect the number of prepositional datives produced $(F 1(1,79)=1.38$, $F 2(1,15)=0.29)$ and did not interact with prime structure $(F 1(1,79)=0.17$, $F 2(1,15)=0.55)$. Because targets were always paired with primes of the opposite thematic type, the non-significant thematic-role effects for targets are also non-significant thematic-role effects for primes. Participants were accurate at the number comparison task, getting $94 \%$ correct on the datives.

\subsection{Discussion}

Speakers were between 5\% (strict coding) and 9\% (standard coding) more likely to produce target sentences as prepositional datives after prepositional dative primes than after double-object primes. The magnitude of structural priming did not change as a function of whether the primes or targets were benefactive or transfer datives. This is consistent with previous findings showing that priming does not require thematic repetition (Bock \& Loebell, 1990), and indicates that the RSVP production task is not necessarily more sensitive to thematic role overlap than the sentence-picture task. Apparently, both tasks tap structural mechanisms of sentence production.

The results also replicate Potter and Lombardi (1998), although our priming effects are considerably smaller in magnitude than theirs (9\% compared to $30 \%$ ). This may be due to the presentation of all the dative targets in double-object form, which is sometimes preferred to the prepositional form (Bock \& Griffin, 2000) or to the frequency of prepositional structures in the experimental lists. Because prepositional datives have the same structure as the sentences in Experiment 1, which was run concurrently, repeated exposure to the structure could have reduced the efficacy of priming (by eliminating the possibility of further implicit learning; Chang, Dell, Bock, \& Griffin, 2000). Also, because the stimuli were drawn from the stimuli in a sentence-picture task, where the prime is auditory and repetition is immediate, the materials were probably not as well matched to the difficult reading and memory demands of the RSVP task as Potter and Lombardi's materials. Even with these constraints, the magnitude of priming with the RSVP task was comparable to the magnitude of priming in a sentence-picture study that incorporated similar manipulations. Dative priming in Bock (1989, Experiment 1) was 0.06; in the present experiment it was between 0.05 (under strict coding) and 0.09 (under standard coding).

\section{General discussion}

In spite of the importance of thematic roles in linguistic theories, there has been little selective support from experimental studies for the use of roles in language production and 
comprehension. Our results suggest that thematic roles may indeed leave memory traces of their places, and this supports the role hypothesis. When the thematic properties of noun phrases varied within a stable structural configuration, subsequent sentences tended to place noun phrases playing analogous roles in analogous positions. The memory traces in question can be viewed as tacit representations of the links between role-players in events and their eventual structural position. Such links are central to a constructional account of functional processing.

The second experiment helped to rule out an explanation of these findings in terms of changes from the methods of other work. The datives in Experiment 2 behaved much as they have in previous studies, with prepositional datives priming other prepositional datives despite differences between primes and targets in their thematic properties.

A constructional account of functional processes suggests that the placement of thematic role-fillers (arguments) in sentences reflects the selection of a construction that is used to map arguments to structural positions. In this approach, the use of a construction increases its likelihood of being used again, and that is one basis for priming. For example, the ability of both prepositional locatives and prepositional datives to prime prepositional datives (Bock \& Loebell, 1990) is consistent with both being instances of the causedmotion construction, differing only in the specifics of verbs and arguments used. The caused-motion construction involves a mapping in which agents map to subjects, themes to objects, and path phrases to oblique prepositional phrases (Goldberg, 1995). These results are therefore consistent with linguistic theories that allow structural configurations to be deployed based on relational meaning (e.g. Culicover, 1999; Fillmore, Kay, \& O'Connor, 1988; Jackendoff, 2002; Lakoff, 1987; Lambrecht, 1994; Langacker, 1987; Michaelis \& Lambrecht, 1996; Sag, 1997; Van Valin \& LaPolla, 1997; Wierzbicka, 1988).

Other linguistic theories could, in principle, accommodate priming results if they allowed lexical entries that abstract over particular verbs. This would permit structural priming to be explained in terms of an increased propensity to use these abstract lexical elements (Davis \& Koenig, 2000; Rappaport Hovav \& Levin, 1998). These abstract entries would essentially mimic the function of constructions. What is essential to account for our results is a way to capture mapping generalizations that are intermediate between lexically specific knowledge and abstract structure-building principles (e.g. X-bar, move-alpha).

Although the data from Experiment 1 contradict the no-roles hypothesis, there is a potential reconciliation of the no-roles view with the current results. The reconciliation requires an elaboration of the approach sketched in Bock et al. (1992). Bock et al. proposed that conceptual features (such as animacy) directly influence the assignment of syntactic functions, without mediation by a declarative representation of thematic roles. On this approach, the results of Experiment 1 could be explained in terms of the conceptual features of themes and locations in the spray-load alternation. While the theme and location did not differ in animacy in Experiment 1, they tend to differ in relative specificity or concreteness: themes in the spray-load alternation are typically mass objects (water, gel, mud) and locations are typically more discrete objects (pan, truck, wagon). If the functional mapping is sensitive to the relative specificity or countability of arguments, our priming results would follow.

Regardless of how the debate between featural and role-based accounts of functional processing is finally resolved, the present experiments are informative about the workings 
of syntactic processes at the interface between meaning and form. Likewise, the findings suggest a tool for exploring these processes, by priming the relationship between semantic properties (either roles or features) and grammatical relations or positions. The evidence that this kind of priming can occur when structural configurations are held constant implies that such forces are normally active within the mapping to sentence forms. This gives weight to a construction-like mechanism as a general, viable account of how, in the course of this mapping, thematically relevant meanings and the forms that convey them interact.

\section{Acknowledgements}

This research formed a part of the author's $\mathrm{PhD}$ dissertation at the University of Illinois at Urbana-Champaign. Preparation of this article was supported by research and training grants from the National Science Foundation (SBR 94-11627 and 98-73450) and the National Institutes of Health (R01 HD21011, T32MH 1819990, and DC-00191). We thank Gary Dell, Victor Ferreira, and three anonymous reviewers for comments on the manuscript, and Heather Pauley and Brooke Biff for help in subject running, transcription, and data coding.

\section{Appendix A. Spray-load items}

Each sentence in each pair occurred as prime and target, in both theme-location and location-theme structure. The sentences are shown in the theme-location version.

\begin{tabular}{ll}
\hline Item & Sentence \\
\hline 1 & The Naval officer draped the flag over the coffin. \\
& Sheila sprinkled some cinnamon onto her toast. \\
& The contractor plastered stucco onto the wall. \\
& The biologist injected an antibiotic into the rat. \\
3 & The performer packed all of his belongings into the suitcase. \\
& The butcher wrapped newspaper around the fish. \\
4 & The undertaker engraved the date onto the tombstone. \\
5 & The chef sprayed oil onto the pan. \\
& The short order cook spattered grease on his apron. \\
6 & The deliveryman loaded boxes onto the truck. \\
& The fashion model powdered rouge onto her cheeks. \\
& The bus splashed water on the pedestrian. \\
& The gardener planted daffodils on the hillside. \\
& The game contestant crammed the dollar bills into his pockets. \\
& The witch doctor stuck pins into the doll. \\
& The home economics teacher brushed butter onto the turkey. \\
& The housecleaner stacked dishes on the countertop. \\
& Dad stuffed treats into the stockings.
\end{tabular}


Appendix (continued)

\begin{tabular}{ll}
\hline Item & Sentence \\
\hline 10 & The maid rubbed polish onto the table. \\
& The farmer heaped straw onto the wagon. \\
& The medic swabbed alcohol onto the wound. \\
& The couple etched their initials into the tree. \\
& The preschooler splattered paint onto the floor. \\
& The policeman jammed the demonstrators into the paddy wagon. \\
& The prankster squirted disappearing ink onto his friend's shirt. \\
& The children tracked mud onto the carpet. \\
& The ranch hand branded a number onto the cow. \\
& The plane dusted insecticide over the crops. \\
& The technician smeared some gel onto the glass slide. \\
& The sailor tattooed a new design onto his arm. \\
& The storm showered hail onto the golf course. \\
& The new resident marked his house number on the gate.
\end{tabular}

\section{Appendix B. Dative items}

Each item contained eight versions that occurred as primes or targets. Two sentences had transfer dative verbs (T1 and T2) and two had benefactive dative verbs (B1 and B2). Prepositional (PD) and double-object (DO) structures served as primes; double-objects served only as targets.

\begin{tabular}{llll}
\hline Item & & \multicolumn{2}{l}{ Conditions Sentences } \\
\hline 1 & T1 & PD & An artist showed a sketch to the police captain. \\
& & DO & An artist showed the police captain a sketch. \\
& T2 & PD & A soldier offered a cigarette to his pal. \\
& DO & A soldier offered his pal a cigarette. \\
& B1 & PD & An artist drew a sketch for the police captain. \\
& DO & An artist drew the police captain a sketch. \\
& B2 & PD & A soldier saved a cigarette for his pal. \\
& DO & A soldier saved his pal a cigarette. \\
& T1 & PD & The caterers awarded a free banquet to the Lions Club. \\
& DO & The caterers awarded the Lions Club a free banquet. \\
& T2 & PD & A carpenter took a little birdhouse to the preschooler. \\
& DO & A carpenter took the preschooler a little birdhouse. \\
& B1 & PD & The caterers fixed a free banquet for the Lions Club. \\
& DO & The caterers fixed the Lions Club a free banquet. \\
& B2 & PD & A carpenter made a little birdhouse for the preschooler. \\
& DO & A carpenter made the preschooler a little birdhouse.
\end{tabular}


Appendix (continued)

\begin{tabular}{|c|c|c|c|}
\hline \multicolumn{3}{|c|}{ Item } & \multirow{2}{*}{$\begin{array}{l}\text { Conditions Sentences } \\
\text { An architect showed a design to the company's president. }\end{array}$} \\
\hline 8 & T1 & PD & \\
\hline & & DO & An architect showed the company's president a design. \\
\hline & $\mathrm{T} 2$ & PD & The manager was taking some peanut brittle to her cousins. \\
\hline & & DO & The manager was taking her cousins some peanut brittle. \\
\hline & B1 & PD & An architect drew a design for the company's president. \\
\hline & & DO & An architect drew the company's president a design. \\
\hline & B2 & PD & The manager was baking some peanut brittle for her cousins. \\
\hline & & DO & The manager was baking her cousins some peanut brittle. \\
\hline \multirow[t]{8}{*}{9} & T1 & PD & The teenager handed a model ship to his brother. \\
\hline & & DO & The teenager handed his brother a model ship. \\
\hline & $\mathrm{T} 2$ & PD & The oil sheik gave a Rolls Royce to his mistress. \\
\hline & & DO & The oil sheik gave his mistress a Rolls Royce. \\
\hline & B1 & PD & The teenager built a model ship for his brother. \\
\hline & & DO & The teenager built his brother a model ship. \\
\hline & B2 & PD & The oil sheik bought a Rolls Royce for his mistress. \\
\hline & & DO & The oil sheik bought his mistress a Rolls Royce. \\
\hline \multirow[t]{8}{*}{10} & T1 & PD & The duchess was loaning a weedeater to the gardener. \\
\hline & & DO & The duchess was loaning the gardener a weedeater. \\
\hline & $\mathrm{T} 2$ & $\mathrm{PD}$ & The principal read a letter of recommendation to the teacher. \\
\hline & & DO & The principal read the teacher a letter of recommendation. \\
\hline & B1 & PD & The duchess was buying a weedeater for the gardener. \\
\hline & & DO & The duchess was buying the gardener a weedeater. \\
\hline & B2 & PD & The principal wrote a letter of recommendation for the teacher. \\
\hline & & DO & The principal wrote the teacher a letter of recommendation. \\
\hline \multirow[t]{8}{*}{11} & T1 & PD & A maid tossed a towel to the hotel guest. \\
\hline & & DO & A maid tossed the hotel guest a towel. \\
\hline & $\mathrm{T} 2$ & PD & A relative gave some flowers to the patient. \\
\hline & & DO & A relative gave the patient some flowers. \\
\hline & B1 & PD & A maid found a towel for the hotel guest. \\
\hline & & DO & A maid found the hotel guest a towel. \\
\hline & B2 & PD & A relative bought some flowers for the patient. \\
\hline & & DO & A relative bought the patient some flowers. \\
\hline \multirow[t]{8}{*}{12} & T1 & PD & The restaurant awarded a dinner to the customer. \\
\hline & & DO & The restaurant awarded the customer a dinner. \\
\hline & $\mathrm{T} 2$ & PD & A rock star sold some pure cocaine to his manager. \\
\hline & & DO & A rock star sold his manager some pure cocaine. \\
\hline & B1 & PD & The restaurant fixed a dinner for the customer. \\
\hline & & DO & The restaurant fixed the customer a dinner. \\
\hline & B2 & PD & A rock star got some pure cocaine for his manager. \\
\hline & & DO & A rock star got his manager some pure cocaine. \\
\hline
\end{tabular}


Appendix (continued)

\begin{tabular}{|c|c|c|c|}
\hline \multicolumn{3}{|c|}{ Item } & \multirow{2}{*}{$\begin{array}{l}\text { Conditions Sentences } \\
\text { The stepfather promised a boomerang to his stepson. }\end{array}$} \\
\hline \multirow[t]{8}{*}{13} & T1 & PD & \\
\hline & & DO & The stepfather promised his stepson a boomerang. \\
\hline & $\mathrm{T} 2$ & PD & A guard tossed some keys to the prison warden. \\
\hline & & DO & A guard tossed the prison warden some keys. \\
\hline & B1 & PD & The stepfather whittled a boomerang for his stepson. \\
\hline & & DO & The stepfather whittled his stepson a boomerang. \\
\hline & B2 & PD & A guard found some keys for the prison warden. \\
\hline & & DO & A guard found the prison warden some keys. \\
\hline \multirow[t]{8}{*}{14} & T1 & PD & A trapper sold some valuable furs to the explorer. \\
\hline & & DO & A trapper sold the explorer some valuable furs. \\
\hline & $\mathrm{T} 2$ & PD & A waitress took a tray of appetizers to the customers. \\
\hline & & DO & A waitress took the customers a tray of appetizers. \\
\hline & B1 & PD & A trapper got some valuable furs for the explorer. \\
\hline & & DO & A trapper got the explorer some valuable furs. \\
\hline & B2 & PD & A waitress made a tray of appetizers for the customers. \\
\hline & & DO & A waitress made the customers a tray of appetizers. \\
\hline \multirow[t]{8}{*}{15} & T1 & PD & The woman was loaning a ladder to her neighbor. \\
\hline & & DO & The woman was loaning her neighbor a ladder. \\
\hline & $\mathrm{T} 2$ & PD & An inventor handed a mousetrap to his elderly mother. \\
\hline & & DO & An inventor handed his elderly mother a mousetrap. \\
\hline & B1 & PD & The woman was buying a ladder for her neighbor. \\
\hline & & DO & The woman was buying her neighbor a ladder. \\
\hline & B2 & PD & An inventor built a mousetrap for his elderly mother. \\
\hline & & DO & An inventor built his elderly mother a mousetrap. \\
\hline \multirow[t]{8}{*}{16} & T1 & PD & The father threw a baseball to his six-year-old. \\
\hline & & DO & The father threw his six-year-old a baseball. \\
\hline & $\mathrm{T} 2$ & PD & A seamstress sent a wedding dress to the bride-to-be. \\
\hline & & DO & A seamstress sent the bride-to-be a wedding dress. \\
\hline & B1 & PD & The father purchased a baseball for his six-year-old. \\
\hline & & DO & The father purchased his six-year-old a baseball. \\
\hline & B2 & PD & A seamstress sewed a wedding dress for the bride-to-be. \\
\hline & & DO & A seamstress sewed the bride-to-be a wedding dress. \\
\hline
\end{tabular}

\section{References}

Anderson, S. R. (1971). On the role of deep structure in semantic interpretation. Foundations of Language, 7 , 387-396.

Bencini, G. M. L., \& Goldberg, A. E. (2000). The contribution of argument structure constructions to sentence meaning. Journal of Memory and Language, 43(4), 640-651.

Bock, J. K. (1986). Syntactic persistence in language production. Cognitive Psychology, 18, 355-387.

Bock, K. (1989). Closed-class immanence in sentence production. Cognition, 31(2), 163-186. 
Bock, K., \& Griffin, Z. M. (2000). The persistence of structural priming: transient activation or implicit learning? Journal of Experimental Psychology: General, 129(2), 177-192.

Bock, K., \& Loebell, H. (1990). Framing sentences. Cognition, 35(1), 1-39.

Bock, K., Loebell, H., \& Morey, R. (1992). From conceptual roles to structural relations: bridging the syntactic cleft. Psychological Review, 99(1), 150-171.

Bresnan, J. (1982). The mental representation of grammatical relations. Cambridge, MA: MIT Press.

Chang, F., Dell, G. S., Bock, K., \& Griffin, Z. M. (2000). Structural priming as implicit learning: a comparison of models of sentence production. Journal of Psycholinguistic Research, 29(2), 217-229.

Chomsky, N. (1981). Lectures on government and binding. Dordrecht: Foris.

Cleland, A. A., \& Pickering, M. J (2002, March). The effects of lexical repetition, semantic relationship, and phonological overlap on the priming of noun phrase structure. Paper presented at the CUNY Sentence Processing Conference, New York, NY.

Cohen, J. D., MacWhinney, B., Flatt, M., \& Provost, J. (1993). PsyScope: a new graphic interactive environment for designing psychology experiments. Behavior Research Methods, Instruments, \& Computers, 25(2), $257-271$.

Culicover, P. W. (1999). Syntactic nuts: hard cases in syntax. Oxford: Oxford University Press.

Davis, A. R., \& Koenig, J. P. (2000). Linking as constraints on word classes in a hierarchical lexicon. Language, $76(1), 56-91$.

Fillmore, C. J., Kay, P., \& O'Connor, M. C. (1988). Regularity and idiomaticity in grammatical constructions: the case of let alone. Language, 64, 501-538.

Garrett, M. F. (1988). Processes in language production. In F. J. Newmeyer (Ed.), Language: psychological and biological aspects (3) (pp. 69-96). Linguistics: the Cambridge survey, Cambridge: Cambridge University Press.

Goldberg, A. E. (1995). Constructions: a construction grammar approach to argument structure. Chicago, IL: University of Chicago Press.

Grimshaw, J. (1990). Argument structure. Cambridge, MA: MIT Press.

Hare, M. L., \& Goldberg, A. E. (2000). Structural priming: purely syntactic? In M. Hahn, \& S. C. Stones (Eds.), (pp. 208-211). Proceedings of the twenty-first annual meeting of the Cognitive Science Society, Mahwah, NJ: Lawrence Erlbaum Associates.

Jackendoff, R. (2002). Foundations of language. Oxford: Oxford University Press.

Lakoff, G. (1987). Women, fire, and dangerous things. Chicago, IL: University of Chicago Press.

Lambrecht, K. (1994). Information structure and sentence form. Cambridge: Cambridge University Press.

Langacker, R. (1987). Foundations of cognitive grammar. Stanford, CA: Stanford University Press.

Levin, B. (1993). English verb classes and alternations: a preliminary investigation. Chicago, IL: University of Chicago Press.

Levin, B., \& Rappaport Hovav, M. (1995). Unaccusativity at the syntax-lexical semantics interface. Cambridge, MA: MIT Press.

Michaelis, L. A., \& Lambrecht, K. (1996). Toward a construction-based model of language function: the case of nominal extraposition. Language, 72, 215-247.

Pickering, M. J., \& Branigan, H. P. (1998). The representation of verbs: evidence from syntactic priming in language production. Journal of Memory and Language, 39, 633-651.

Pinker, S. (1989). Learnability and cognition: the acquisition of argument structure. Cambridge, MA: MIT Press.

Potter, M. C., \& Lombardi, L. (1998). Syntactic priming in immediate recall of sentences. Journal of Memory and Language, 38(3), 265-282.

Rappaport, M., \& Levin, B (1985). A study in lexical analysis: the locative alternation. Unpublished manuscript, Bar Ilan University and Northwestern University.

Rappaport Hovav, M., \& Levin, B. (1998). Building verb meanings. In M. Butt, \& W. Geuder (Eds.), The projection of arguments: lexical and compositional factors. Stanford, CA: CSLI.

Sag, I. A. (1997). English relative clause constructions. Journal of Linguistics, 33(2), 431-484.

Van Valin, R. D. J., \& LaPolla, R. J. (1997). Syntax. Structure, meaning and function. Cambridge: Cambridge University Press.

Wierzbicka, A. (1988). The semantics of grammar. Amsterdam: John Benjamins.

Winer, B. J. (1971). Statistical principles in experimental design. New York: McGraw-Hill. 